\title{
The Role of Endoscopic Ultrasound in the Diagnosis and Management of Primary Gastric Lymphoma
}

\author{
Dimitrios Schizas, ${ }^{1}$ Ioannis Ntanasis-Stathopoulos, ${ }^{2}$ Diamantis I. Tsilimigras, ${ }^{2}$ \\ Athanasios D. Sioulas, ${ }^{3}$ Demetrios Moris, ${ }^{4}$ Eleftherios Spartalis, ${ }^{5}$ Ilias Scotiniotis, ${ }^{3}$ and \\ Ioannis S. Papanikolaou ${ }^{6}$ \\ ${ }^{1}$ First Department of Surgery, Laikon General Hospital, National and Kapodistrian University of Athens, Athens, Greece \\ ${ }^{2}$ School of Medicine, National and Kapodistrian University of Athens, Athens, Greece \\ ${ }^{3}$ Department of Gastroenterology, Hygeia Hospital, Athens, Greece \\ ${ }^{4}$ Department of Immunology, Lerner Research Institute, Cleveland Clinic, Cleveland, OH, USA \\ ${ }^{5}$ Second Department of Propaedeutic Surgery, National and Kapodistrian University of Athens, Athens, Greece \\ ${ }^{6}$ Hepatogastroenterology Unit, Second Department of Internal Medicine and Research Unit, "Attikon” University General Hospital \\ and National and Kapodistrian University of Athens, Haidari, Greece \\ Correspondence should be addressed to Athanasios D. Sioulas; athsioulas@yahoo.gr
}

Received 2 January 2017; Accepted 22 February 2017; Published 16 March 2017

Academic Editor: Alfred Gangl

Copyright (c) 2017 Dimitrios Schizas et al. This is an open access article distributed under the Creative Commons Attribution License, which permits unrestricted use, distribution, and reproduction in any medium, provided the original work is properly cited.

Endoscopic ultrasound (EUS) is considered a valuable diagnostic tool during the workup of malignant gastric lesions, including primary gastric lymphomas (PGL). Although endoscopy combined with multiple biopsies remains essential in the establishment of PGL diagnosis, EUS utilization in locoregional disease staging has been well documented in the literature. Data also support the possible role of EUS in prediction of response to first-line treatment, that is, Helicobacter pylori eradication. However, its application in the posttreatment setting remains problematic, since concordance rates between endosonography and histology findings during follow-up seem to vary substantially. The aim of the present review is to summarize all available data regarding the role of EUS in the management of PGL.

\section{Introduction}

Non-Hodgkin lymphoma (NHL) consists of a diverse group of malignancies originating from the lymphoid tissue and deriving from the clonal expansion of B-cells, T-cells, natural killer (NK) cells, or their precursors. Most NHL present with disease located in lymph nodes, which comprise about $65-80 \%$ of all cases $[1,2]$. On the other hand, primary extranodal NHL, by definition, involves organs or tissues other than lymph nodes or spleen. Amongst them, gastrointestinal lymphoma accounts for the $30-40 \%$ of cases. The most frequently involved site is the stomach (60-75\%) followed by the small bowel, ileum, cecum, colon, and rectum $[1,3]$. The vast majority (greater than $90 \%$ ) of primary gastric lymphomas (PGL) are equally divided into two major histologic subtypes: mucosa-associated lymphoid tissue (MALT) and diffuse large B-cell lymphoma (DLBCL). The remaining cases include mantle cell (1\%), follicular cell (0.5-2\%), and peripheral T-cell lymphomas (1.5-4\%) [4-6].

Gastric MALT lymphoma comprises about $50 \%$ of PGL. Although a strong association with chronic Helicobacter pylori infection had been initially demonstrated [7], recent data have shown that the incidence of $H$. pylori-positive lymphomas has remarkably declined during the last decades reaching to $35 \%$ approximately [8]. In these cases that are unlikely to respond to $H$. pylori eradication treatment, there are additional therapeutic options with favorable efficacy including radiotherapy, chemotherapy, and immunotherapy $[9,10]$. Current treatment strategies take into account both the presence of $H$. pylori and the stage of the disease. It has 
Table 1: Comparison of Ann Arbor, Lugano, and Paris (TNM) classification systems.

\begin{tabular}{|c|c|c|c|c|}
\hline & Ann Arbor staging system & Lugano classification & $\begin{array}{c}\text { Paris classification } \\
\text { (TNM) }\end{array}$ & Lymphoma extension \\
\hline IE1 & Confined to mucosa, submucosa & \multirow[b]{2}{*}{ Stage I } & \multirow[b]{2}{*}{ T1-T3N0M0 } & \multirow{2}{*}{$\begin{array}{l}\text { Confined to GI tract (mucosa, } \\
\text { submucosa, muscularis propria, } \\
\text { and serosa) }\end{array}$} \\
\hline IE2 & $\begin{array}{l}\text { Confined to the stomach, invasion } \\
\text { of the muscularis and/or serosa }\end{array}$ & & & \\
\hline IIE1 & $\begin{array}{l}\text { Involvement of the stomach and } \\
\text { contiguous lymph nodes }\end{array}$ & \multirow{3}{*}{$\begin{array}{c}\text { Stage II } \\
\text { II1: local nodal involvement } \\
\text { II2: distant nodal involvement }\end{array}$} & \multirow{3}{*}{$\begin{array}{l}\mathrm{T} 1-\mathrm{T} 3 \mathrm{~N} 1 \mathrm{M} 0 \\
\mathrm{~T} 1-\mathrm{T} 3 \mathrm{~N} 2 \mathrm{M} 0\end{array}$} & Extending into the abdomen \\
\hline \multirow[b]{2}{*}{ IIE2 } & \multirow{2}{*}{$\begin{array}{l}\text { Involvement of the stomach and } \\
\text { noncontiguous subdiaphragmatic } \\
\text { lymph nodes }\end{array}$} & & & Perigastric lymph nodes \\
\hline & & & & More distant regional lymph nodes \\
\hline \multirow{2}{*}{ IIIE } & \multirow{2}{*}{$\begin{array}{l}\text { Involvement of the stomach } \\
\text { and lymph nodes on both sides } \\
\text { of the diaphragm }\end{array}$} & \multirow{2}{*}{ Stage III } & T4N0M0 & $\begin{array}{l}\text { Penetrating of serosa and } \\
\text { adjacent organs }\end{array}$ \\
\hline & & & T1-T4N3M0 & $\begin{array}{l}\text { Lymph nodes on both sides } \\
\text { of the diaphragm }\end{array}$ \\
\hline IVE & Hematogenous spread & Stage IV & T1-T4N0-N3M1 & Distant metastasis (e.g., bone marrow) \\
\hline
\end{tabular}

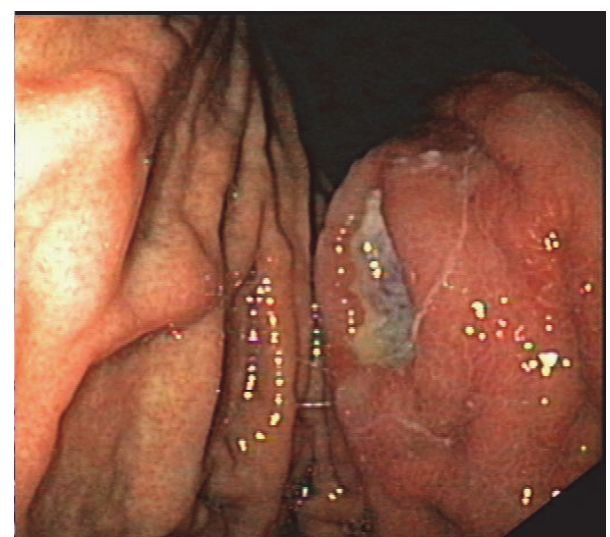

FIGURE 1: Endoscopic image of primary gastric lymphoma.

to be noted that several staging systems have been proposed throughout the years (Table 1) [11-13]. In that context, endoscopic ultrasound (EUS) of the stomach has emerged as one of the best tools for locoregional staging in PGL. Indeed, several studies have demonstrated its high accuracy in the initial staging and, possibly, the prediction of response to treatment and posttreatment follow-up $[14,15]$.

In this review, we aimed to present the available data regarding the role of EUS in PGL both in the diagnostic and posttreatment settings.

1.1. Diagnosis and Locoregional Staging. Patients suffering from PGL usually present with nonspecific upper gastrointestinal (GI) complaints, such as vague abdominal pain, melena, and hematemesis that eventually lead to an extensive diagnostic workup including endoscopic series. Endoscopy may not detect the neoplastic lesion, as it can develop in deeper GI layers; however, when combined with multiple biopsies taken from different sites, such as the stomach, gastroesophageal junction, duodenum, and abnormal-appearing areas, its efficacy in the diagnostic procedure significantly increases [16]. As the endoscopic appearance of a PGL varies from normal gastric pattern or subtle mucosal irregularities to large ulcers, a high index of suspicion is rendered crucial in order to reach an accurate diagnosis (Figure 1). Accordingly, endosonographic features of PGL may either be initially invisible or vary from a thickening of the inner two or three layers to a diffuse wall thickening, with or without preservation of the typical 5-layer structure (even if the layers are thickened or distorted, with an irregular, but relatively well-preserved outer margin) (Figures 2(a) and $2(\mathrm{~b}))[5,6]$.

Furthermore, it has to be highlighted that EUS pattern may correlate with the histologic subtype of PGL. Indeed, Suekane et al. showed that superficial spreading or diffuseinfiltrating lesions on EUS were associated with MALT lymphoma, while mass-forming lesions were associated with gastric DLBCL [17]. Given the small cohort of patients included in this study, however, this evidence cannot directly be applied in clinical practice. In general, endoscopy combined with multiple biopsies is considered - to date-the gold standard in diagnosing an abnormal-appearing lesion, which is essential for determining the appropriate treatment [18].

Currently, EUS is considered the method of choice for locoregional staging of PGL, including the detection of affected perigastric lymph nodes. It has been shown that EUS is superior to CT scan in this setting due to higher sensitivity both in detecting lymph node involvement as well as subtle differences regarding gastric layers and wall thickness [19]. This is of great importance since locoregional staging is one of the major factors that can predict the response to treatment, that is, the identification of patients whose disease is likely to be refractory to treatment or to recur.

Another aspect of EUS staging in PGL is the evaluation of lymph node involvement. Regional lymph nodes as well as those beyond the regional area may be demonstrated with EUS. Their characterization as affected or nonaffected by lymphoma is initially decided according to the classical Bmode criteria indicating malignancy, namely, hypoechoic structure, sharply demarcated borders, rounded contour, and size $>1 \mathrm{~cm}$. These criteria were established in the $1990 \mathrm{~s}$ for esophageal carcinoma, but their use has been widely extrapolated for any type of malignancy including prediction of lymph node infiltration [20]. 


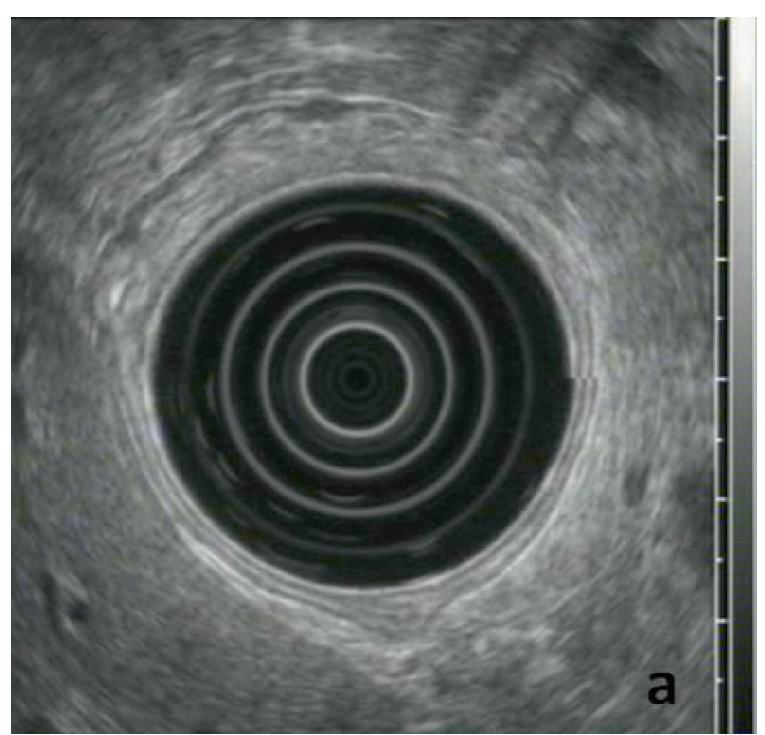

(a)

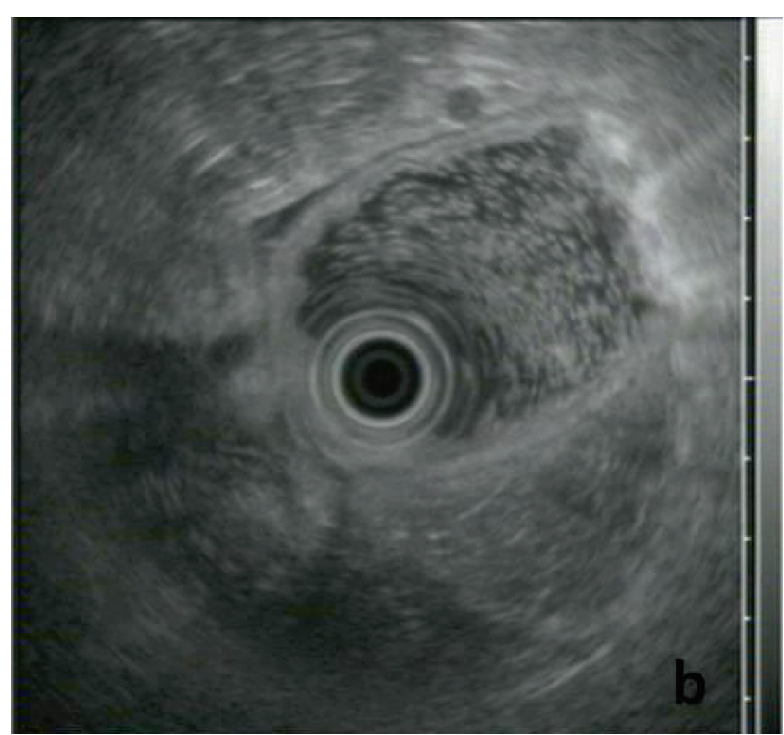

(b)

FIgURE 2: (a) Radial-EUS imaging of the gastric wall; notice the normal 5-layer structure. (b) Radial-EUS imaging in primary gastric lymphoma; notice the disappearance of the normal 5-layer structure at the point where the EUS transducer comes into contact with the gastric wall (9 to 6 o'clock position).

Although these criteria were extremely useful at the time they were set, modern noninvasive improvements including contrast enhancement and elastography have been introduced in an attempt to improve the accuracy of EUS for $\mathrm{N}$ staging. In a study from Germany, contrast-enhanced EUS showed improvement in diagnosing benign lymph nodes compared to standard EUS, but it did not increase the accuracy in detecting malignant lymph nodes [21]. Additionally, elastography is a technique that offers information on mechanical properties of the examined tissue by measuring mechanically induced deformations (i.e., strain) of structures in B-mode images in order to quantify the elasticity of the tissue. It was introduced in EUS imaging as a promising approach, since it could enable a noninvasive method in the $\mathrm{N}$ staging, based on the fact that malignant lymph nodes are generally "harder" than their nonmalignant counterparts [22]. This technique has been validated for metastatic carcinomas [23], as well as primary carcinomas per se [24], increasing the accuracy of EUS in detecting malignant lymph nodes to $85 \%$. However, data regarding its use in PGL is still limited. Although the advent of up-to-date technology in EUS instruments is highly appreciated, the limited available data from the literature prevent its wide application in everyday clinical practice.

Literature from the early 1990s had determined the accuracy of EUS for PGL T and N staging at a level of approximately $90 \%$ and $80 \%$, respectively [14, 15]. However, in 2002, a multicenter study incorporating data from 34 centers (including 70 patients) showed that the overall accuracy of EUS in determining the stage (according to modified Ann Arbor classification) was 53\%. Nevertheless, it has to be noted that the majority of examiners in most centers were probably not experienced in PGL staging, as indicated by the fact that only five out of 34 centers recruited more than
2 patients in the study [25]. Although this study may falsely underestimate the role of EUS in locoregional staging of PGL, it highlights the well-known problem of operator's expertise during EUS staging. According to recent guidelines, improvement in EUS training along with recent advances in EUS technology, namely, electronic instead of mechanical EUS imaging, Doppler ultrasound, elastography, and lately the use of intravenous contrast medium for EUS, could possibly increase the efficacy of this modality, even in the hands of less experienced examiners [26]. Another intriguing issue affecting the quality of EUS staging is the reproducibility of its results; in a study examining interobserver agreement, the authors concluded that it was at an acceptable level for T staging (kappa: 0.38) and substantial for $\mathrm{N}$ staging (kappa: 0.63 ), whereas the lowest values of agreement were detected for T1sm (submucosa) and T2 stage lesions (kappa: 0.330.35) [27]. However, it must be stressed that these results come from a center with specialists in the field and these do not always reflect the daily clinical practice.

Overall, two main factors seem to strongly influence the reproducibility of EUS findings: training and experience. Apart from the above, it has to be underlined that regular good quality endoscopic biopsy sampling is of utmost importance. In the era of molecular characterization of lymphomas that is associated with predictive and prognostic aspects, it is very important to assure the availability of a diagnostic material [28].

1.2. Is There a Role for EUS-FNA? Several years ago, the advent of EUS-guided fine needle aspiration (FNA) biopsy provided new possibilities for transmural tissue diagnosis. This technique allows for cytological examination of the specimen, in contrast to the endoscopic biopsy that refers to histological evaluation. Although EUS-FNA seems to be 
efficient in mediastinal and intra-abdominal malignancies [29-31], its exact role in the staging of PGL has not been formally investigated and is highly debatable. Nevertheless, two studies have demonstrated its importance in the diagnosis of nodal lymphoma; the first revealed the high diagnostic accuracy of EUS-FNA when combined with flow cytometry and immunocytochemistry, but it was limited by its retrospective nature and the rather small number of patients (i.e., 38, 23 with lymphoma, and 15 patients with benign disease or reactive lymphadenopathy) [32]. The second was a Japanese study involving a total of 104 patients with mediastinal and/or intra-abdominal lymphadenopathy of unknown origin that demonstrated a high accuracy for EUS-FNA in achieving the appropriate diagnosis (48/50 lymphomas, i.e., $96 \%$ ) and a similar ability to correctly classify the lymphomas in 44/50 of cases (88\%) [29]. Though not explicitly reporting on PGL, both studies indicate that EUS-FNA could aid in determining nodal involvement in this setting.

There are, however, limitations owing to the intrinsic properties of this technique. There remain concerns that only a limited amount of tissue can be removed with EUS-FNA, thus reducing its diagnostic ability. This could be overcome by using needles with a larger caliber (e.g., 19-gauge), which allow tissue acquisition, histologic evaluation, and subsequent classification of lymphoid tissue malignancies. Furthermore, it has been shown that subclassification of lymphomas solely by EUS-FNA is feasible only in $66 \%$ of cases yielding the lowest accuracy regarding low-grade lymphomas. The proper distinction between benign hyperplasia and low-grade lymphomas based solely on morphological or immunohistochemical features has been questioned [33]. Additionally, it is difficult during EUS to determine the most appropriate lymph nodes to perform sampling in low-grade lymphomas, due to the fact that echogenic properties in these cases are of limited value and only size may be used as a guide. In contrast to these restrictions, cytological diagnosis is more feasible in high-grade lymphomas/DLBCL [33]. Lastly, there is yet no comparative study examining EUS-FNA with the standard histologic evaluation, in order to clearly define the superiority or inferiority of this approach.

1.3. Prediction of Response to Treatment with EUS. Current guidelines favor the administration of $H$. pylori eradication regimens as the first-line treatment in $H$. pylori-positive patients irrespective of tumor stage $[9,10]$. As aforementioned, locoregional staging is associated with the prediction of response to treatment and, therefore, EUS may provide valuable prognostic information in this setting. Regarding MALT lymphoma, EUS-based staging confers prognostic value as localized disease seems to respond well to $H$. pylori eradication treatment, while advanced disease shows greater resistance to therapy $[10,34,35]$. However, there are some reports of complete disease regression after $H$. pylori eradication in lymphomas of even more advanced stages [32]. It should be noted that the complete regressions occurring in these cases (3/5 patients with stage EII gastric MALT lymphomas) could be a result of overstaging due to reactive inflammation that led to echo-poor wall infiltration beyond the limits of the lymphoid tissue or due to reactive enlargement of lymph nodes [32]. It has also to be underscored that PGL staging might be of higher value in DLBCL subtype. EUS staging along with molecular biomarkers may be the basis for determining the probability of response to $H$. pylori eradication treatment solely, before proceeding to systemic therapy that is usually necessary in patients with DLBCL [36].

1.4. The Role of EUS in the Posttreatment Follow-Up. Data regarding the role of EUS in the follow-up of gastric lymphoma after treatment seem to be controversial. Initial studies from the time when chemotherapy was an option even for early stage low-grade gastric MALT lymphomas showed that EUS is a reliable method in assessing response to chemotherapy [37]. However, more recent publications showed that an echo-poor infiltration of the gastric layers might persist for more than 6 months despite complete disease remission; therefore, persistence of an EUS abnormality in the gastric wall structure with a negative histology should not imply evidence of disease requiring further treatment per se. Interestingly, the endosonographic appearance of the wall structure may appear normal despite the presence of lymphoma resistant to therapy. At least two well-conducted studies have confirmed these findings by showing that standard endoscopic biopsies were superior to EUS in the monitoring of patients with PGL $[38,39]$. It should be also mentioned that the concordance rates between EUS and histological findings during the follow-up period vary substantially in the literature, and, thus, concerns are raised [19]. Due to the inferior accuracy rates reported for EUS compared to histology, repeated upper GI endoscopy with biopsies every 6 months for the first 2 years and then annually is considered sufficient for the follow-up of patients with PGL $[40,41]$.

\section{Conclusion}

EUS constitutes a valuable diagnostic tool during the staging workup of PGL, which has shown superiority over the CT scan regarding the locoregional disease assessment. In this setting, EUS may provide important information on prognostic features of the disease and may contribute to the determination of the therapeutic approach. To date, its role in the assessment of disease response to treatment remains rather limited and controversial. However, taken into consideration the vivid interest of the scientific community on this issue, future multicenter collaborative studies are necessary in order to shed light into the role of EUS in the management of PGL.

\section{Conflicts of Interest}

The authors declare that there is no conflict of interest regarding the publication of this paper.

\section{References}

[1] S. M. Ansell, "Non-Hodgkin lymphoma: diagnosis and treatment," Mayo Clinic Proceedings, vol. 90, no. 8, pp. 11521163, 2015. 
[2] T. Anderson, B. A. Chabner, R. C. Young et al., "Malignant lymphoma. 1. The histology and staging of 473 patients at the National Cancer Institute," Cancer, vol. 50, no. 12, pp. 2699-2707, 1982.

[3] W. J. Loehr, Z. Mujahed, F. D. Zahn, G. F. Gray, and B. Thorbjarnarson, "Primary lymphoma of the gastrointestinal tract: a review of 100 cases," Annals of Surgery, vol. 170, no. 2, pp. 232-238, 1969.

[4] J. Janssen, "The impact of EUS in primary gastric lymphoma," Best Practice \& Research. Clinical Gastroenterology, vol. 23, no. 5, pp. 671-678, 2009.

[5] P. Fusaroli and G. Caletti, "EUS in the evaluation of gastric wall layer abnormalities-non-Hodgkin lymphoma and other causes," in Endosonography, R. H. Hawes and P. Fockens, Eds., pp. 99-110, Saunders Elsevier, 2006.

[6] H. Li and R. C, "Gastrointestinal lymphomas," in Sleisenger \& Fordtran's Gastrointestinal and Liver Disease: Pathophysiology, Diagnosis, Management, M. Feldman, L. S. Friedman and L. J. Brandt, Eds., pp. 445-453, Elsevier Science, USA, 2010.

[7] A. C. Wotherspoon, C. Ortiz-Hidalgo, M. R. Falzon, and P. G. Isaacson, "Helicobacter pylori-associated gastritis and primary B-cell gastric lymphoma," Lancet, vol. 338, no. 8776, pp. 1175-1176, 1991.

[8] L. Sena Teixeira Mendes, A. D Attygalle, and A. C Wotherspoon, "Helicobacter pylori infection in gastric extranodal marginal zone lymphoma of mucosa-associated lymphoid tissue (MALT) lymphoma: a re-evaluation," Gut, vol. 63, no. 9, pp. 1526-1527, 2014.

[9] E. Zucca, C. Copie-Bergman, U. Ricardi et al., "Gastric marginal zone lymphoma of MALT type: ESMO clinical practice guidelines for diagnosis, treatment and follow-up," Annals of Oncology, vol. 24, Supplement 6, pp. vi144-vi148, 2013.

[10] A. Ruskone-Fourmestraux, W. Fischbach, B. M. Aleman et al., "EGILS consensus report. Gastric extranodal marginal zone B-cell lymphoma of MALT," Gut, vol. 60, no. 6, pp. 747758, 2011.

[11] T. Radaszkiewicz, B. Dragosics, and P. Bauer, "Gastrointestinal malignant lymphomas of the mucosa-associated lymphoid tissue: factors relevant to prognosis," Gastroenterology, vol. 102, no. 5, pp. 1628-1638, 1992.

[12] A. Rohatiner, F. d'Amore, B. Coiffier et al., "Report on a workshop convened to discuss the pathological and staging classifications of gastrointestinal tract lymphoma," Annals of Oncology, vol. 5, no. 5, pp. 397-400, 1994.

[13] A. Ruskone-Fourmestraux, B. Dragosics, A. Morgner, A. Wotherspoon, and D. De Jong, "Paris staging system for primary gastrointestinal lymphomas," Gut, vol. 52, no. 6, pp. 912-913, 2003.

[14] G. Caletti, A. Ferrari, E. Brocchi, and L. Barbara, "Accuracy of endoscopic ultrasonography in the diagnosis and staging of gastric cancer and lymphoma," Surgery, vol. 113, no. 1, pp. 14-27, 1993.

[15] L. Palazzo, G. Roseau, A. Ruskone-Fourmestraux et al., "Endoscopic ultrasonography in the local staging of primary gastric lymphoma," Endoscopy, vol. 25, no. 8, pp. 502-508, 1993.

[16] W. Fischbach, "Gastric MALT lymphoma-update on diagnosis and treatment," Best Practice \& Research. Clinical Gastroenterology, vol. 28, no. 6, pp. 1069-1077, 2014.

[17] H. Suekane, M. Iida, T. Yao, T. Matsumoto, Y. Masuda, and M. Fujishima, "Endoscopic ultrasonography in primary gastric lymphoma: correlation with endoscopic and histologic findings," Gastrointestinal Endoscopy, vol. 39, no. 2, pp. 139-145, 1993.

[18] E. Zucca, M. Dreyling, and Group EGW, "Gastric marginal zone lymphoma of MALT type: ESMO clinical practice guidelines for diagnosis, treatment and follow-up," Annals of Oncology, vol. 21, Supplement 5, pp. v175-v176, 2010.

[19] C. Vetro, A. Chiarenza, A. Romano et al., "Prognostic assessment and treatment of primary gastric lymphomas: how endoscopic ultrasonography can help in tailoring patient management," Clinical Lymphoma, Myeloma \& Leukemia, vol. 14, no. 3, pp. 179-185, 2014.

[20] M. F. Catalano, M. V. Sivak Jr., T. Rice, L. A. Gragg, and J. Van Dam, "Endosonographic features predictive of lymph node metastasis," Gastrointestinal Endoscopy, vol. 40, no. 4, pp. 442-446, 1994.

[21] M. Hocke, M. Menges, T. Topalidis, C. F. Dietrich, and A. Stallmach, "Contrast-enhanced endoscopic ultrasound in discrimination between benign and malignant mediastinal and abdominal lymph nodes," Journal of Cancer Research and Clinical Oncology, vol. 134, no. 4, pp. 473-480, 2008.

[22] M. Giovannini, L. C. Hookey, E. Bories, C. Pesenti, G. Monges, and J. R. Delpero, "Endoscopic ultrasound elastography: the first step towards virtual biopsy? Preliminary results in 49 patients," Endoscopy, vol. 38, no. 4, pp. 344-348, 2006.

[23] J. Janssen, C. F. Dietrich, U. Will, and L. Greiner, "Endosonographic elastography in the diagnosis of mediastinal lymph nodes," Endoscopy, vol. 39, no. 11, pp. 952-957, 2007.

[24] Hirche TO, A. Ignee, A. P. Barreiros et al., "Indications and limitations of endoscopic ultrasound elastography for evaluation of focal pancreatic lesions," Endoscopy, vol. 40, no. 11, pp. 910-917, 2008.

[25] W. Fischbach, M. E. Goebeler-Kolve, and A. Greiner, "Diagnostic accuracy of EUS in the local staging of primary gastric lymphoma: results of a prospective, multicenter study comparing EUS with histopathologic stage," Gastrointestinal Endoscopy, vol. 56, no. 5, pp. 696-700, 2002.

[26] J. M. Dumonceau, M. Polkowski, A. Larghi et al., "Indications, results, and clinical impact of endoscopic ultrasound (EUS)guided sampling in gastroenterology: European Society of Gastrointestinal Endoscopy (ESGE) Clinical Guideline," Endoscopy, vol. 43, no. 10, pp. 897-912, 2011.

[27] P. Fusaroli, E. Buscarini, S. Peyre et al., "Interobserver agreement in staging gastric malt lymphoma by EUS," Gastrointestinal Endoscopy, vol. 55, no. 6, pp. 662-668, 2002.

[28] J. O. Armitage, R. D. Gascoyne, M. A. Lunning, and F. Cavalli, "Non-Hodgkin lymphoma," Lancet, 2017.

[29] I. Yasuda, H. Tsurumi, S. Omar et al., "Endoscopic ultrasoundguided fine-needle aspiration biopsy for lymphadenopathy of unknown origin," Endoscopy, vol. 38, no. 9, pp. 919-924, 2006.

[30] M. Al-Haddad and M. B. Wallace, "EUS-FNA and biomarkers for the staging of non-small cell lung cancer," Endoscopy, vol. 38, Supplement 1, pp. S114-S117, 2006.

[31] P. Vilmann, F. Herth, and M. Krasnik, "State of the art lecture: mediastinal EUS," Endoscopy, vol. 38, Supplement 1, pp. S84-S87, 2006.

[32] S. Nakamura, T. Matsumoto, H. Suekane et al., "Predictive value of endoscopic ultrasonography for regression of gastric low grade and high grade MALT lymphomas after eradication of Helicobacter pylori," Gut, vol. 48, no. 4, pp. 454-460, 2001.

[33] A. Ribeiro, D. Pereira, M. P. Escalon, M. Goodman, and G. E. Byrne Jr, "EUS-guided biopsy for the diagnosis and 
classification of lymphoma," Gastrointestinal Endoscopy, vol. 71, no. 4, pp. 851-855, 2010.

[34] M. Sackmann, A. Morgner, B. Rudolph et al., "Regression of gastric MALT lymphoma after eradication of Helicobacter pylori is predicted by endosonographic staging. MALT Lymphoma Study Group," Gastroenterology, vol. 113, no. 4, pp. 1087-1090, 1997.

[35] A. J. Ferreri, S. Govi, M. Raderer et al., "Helicobacter pylori eradication as exclusive treatment for limited-stage gastric diffuse large B-cell lymphoma: results of a multicenter phase 2 trial," Blood, vol. 120, no. 18, pp. 3858-3860, 2012.

[36] S. Paydas, "Helicobacter pylori eradication in gastric diffuse large B cell lymphoma," World Journal of Gastroenterology, vol. 21, no. 13, pp. 3773-3776, 2015.

[37] M. Levy, P. Hammel, D. Lamarque et al., "Endoscopic ultrasonography for the initial staging and follow-up in patients with low-grade gastric lymphoma of mucosa-associated lymphoid tissue treated medically," Gastrointestinal Endoscopy, vol. 46, no. 4, pp. 328-333, 1997.

[38] F. Di Raimondo, L. Caruso, G. Bonanno et al., "Is endoscopic ultrasound clinically useful for follow-up of gastric lymphoma?" Annals of Oncology, vol. 18, no. 2, pp. 351-356, 2007.

[39] A. Puspok, M. Raderer, A. Chott, B. Dragosics, A. Gangl, and R. Schöfl, "Endoscopic ultrasound in the follow up and response assessment of patients with primary gastric lymphoma," Gut, vol. 51, no. 5, pp. 691-694, 2002.

[40] E. J. Kuipers, "When is endoscopic follow-up appropriate after Helicobacter pylori eradication therapy?" Gastroenterology Clinics of North America, vol. 44, no. 3, pp. 597-608, 2015.

[41] J. Y. Choi, G. H. Lee, J. Y. Ahn et al., "The role of abdominal CT scan as follow-up after complete remission with successful Helicobacter pylori eradication in patients with $\mathrm{H}$. pyloripositive stage I(E1) gastric MALT lymphoma," Helicobacter, vol. 16, no. 1 , pp. 36-41, 2011. 


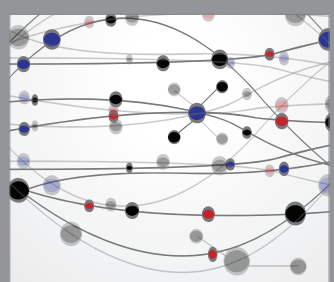

The Scientific World Journal
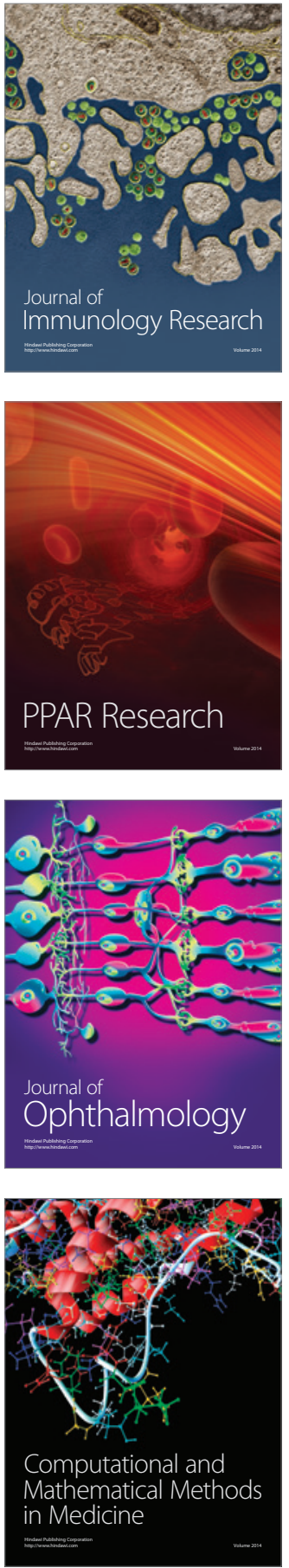

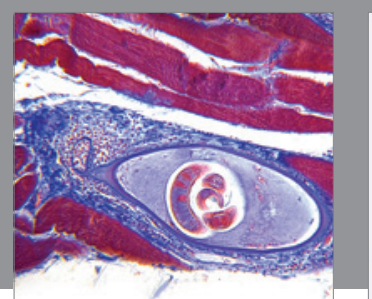

Gastroenterology Research and Practice
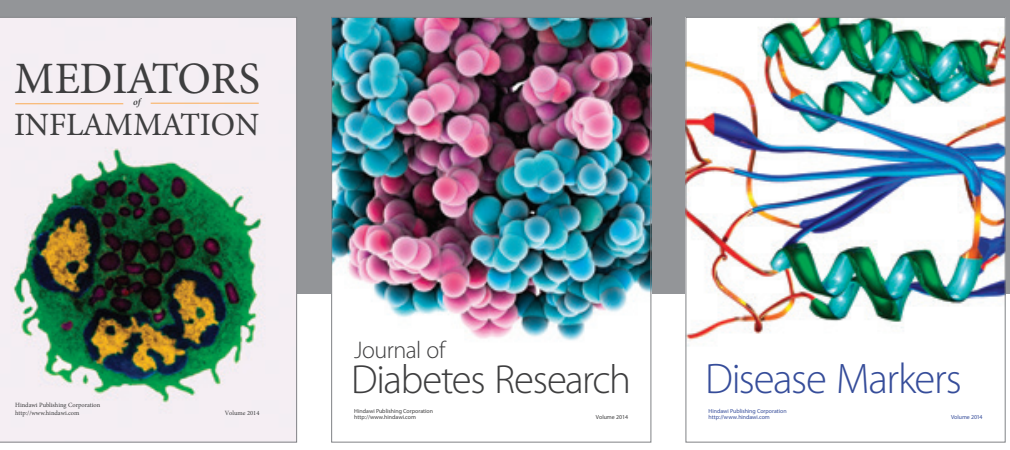

Disease Markers

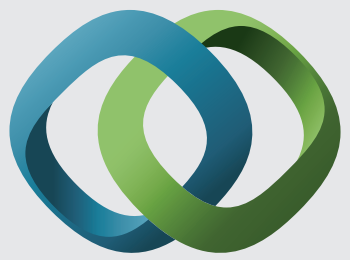

\section{Hindawi}

Submit your manuscripts at

https://www.hindawi.com
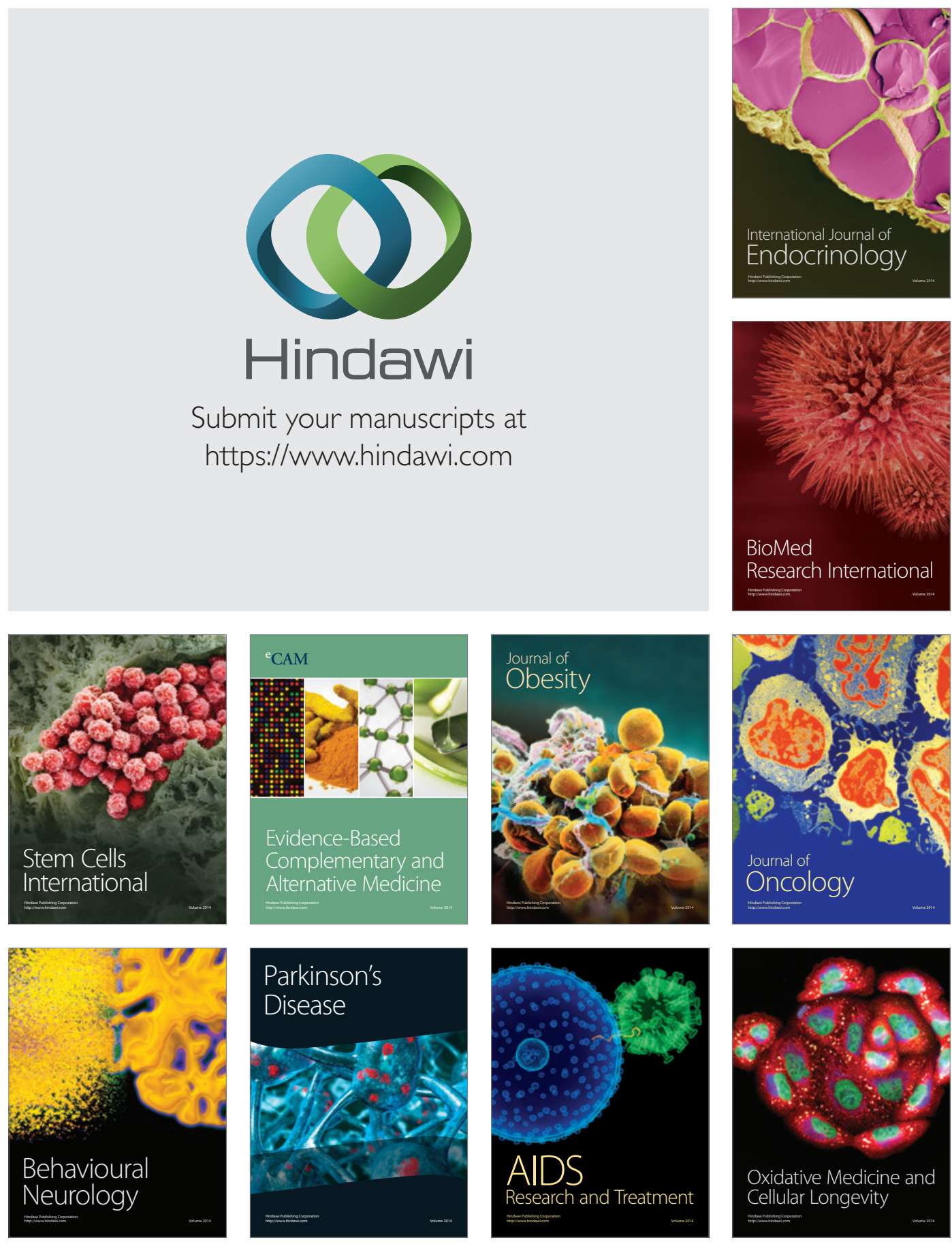